\title{
Correlation between Selenium and Heavy Metal Content in Camellia oleifera in Hainan, China
}

\author{
Jun Yuan ${ }^{1,2}$, Deyi Yuan ${ }^{1,2}$, Xiaofeng Tan ${ }^{1,2, *}$, Feng Zou ${ }^{1}$ and Shixin Xiao $^{2}$ \\ ${ }^{I}$ Hunan Provincial Cooperative Innovation Center of Non-wood Forest Cultivation and Utilization, Central South \\ University of Forestry and Technology, Changsha, Hunan, 410004, China \\ ${ }^{2}$ Key Laboratory of Cultivation and Protection for Non-Wood Forest Trees (Central South University of Forestry and \\ Technology), Ministry of Education, Changsha, Hunan, 410004, China
}

\begin{abstract}
Eighteen forests of Camellia oleifera in Hainan province, China were selected to measure the contents of selenium $(\mathrm{Se})$, zinc $(\mathrm{Zn})$, mercury $(\mathrm{Hg})$, cadmium $(\mathrm{Cd})$, chromium $(\mathrm{Cr})$, lead $(\mathrm{Pd})$ and arsenic $(\mathrm{As})$ in soils, roots, leaves, and kernels, and analyze the correlation between the soil content and the corresponding content in the plant. It was found that the content of Se in soils ranged between 0.489 and $2.110 \mathrm{mg} / \mathrm{kg}$, and was higher than $1.0 \mathrm{mg} / \mathrm{kg}$ in 10 out of 18 forests. The average content of six heavy metals was low and fulfilled the requirements of soil environment for green-food production, except that the contents of $\mathrm{Cr}, \mathrm{Pb}$, and $\mathrm{Cd}$ exceeded standards in few regions. The content of Se in Camellia oleifera was relatively low. Only five regions showed detectable levels of Se in kernels, with the highest in Fuwen Town of Dingan county of $0.085 \mathrm{mg} / \mathrm{kg}$. The contents of $\mathrm{Zn}, \mathrm{Cr}, \mathrm{Pb}, \mathrm{Cd}$, As, and $\mathrm{Hg}$ in roots of Camellia oleifera were higher than in the leaves and kernels. The contents of $\mathrm{Zn}, \mathrm{Cr}$, and $\mathrm{Pb}$ were higher than that of $\mathrm{Cd}$, As, and $\mathrm{Hg}$. The As content in soil was in significant correlation with that in the roots of Camellia oleifera. The Pd content in the soil was positively correlated with that of the roots of Camellia oleifera. The $\mathrm{Cr}$, $\mathrm{Pd}$ and $\mathrm{Cd}$ contents in roots were in positive correlation with that in the leaves significantly. However, the $\mathrm{Hg}$ content of the roots was positively correlated with that of the kernels. Furthermore, the Se content in roots of Camellia oleifera was negatively associated with that of the other six heavy metals, having a significantly negative correlation between Se and As.
\end{abstract}

Keywords: Correlation, Hainan province, Heavy metal, Oiltea, Selenium.

\section{INTRODUCTION}

Soil is an integral part of human ecological environment, and the foundation of agriculture and forestry production. Heavy metal pollution adversely affects the growth and development of plants and the quality of agricultural products [1]. Studies on rice [2] and persimmon [3] suggested that Se not only reduced the uptake of heavy metals such as cadmium $(\mathrm{Cd})$ and lead $(\mathrm{Pd})$, but also exerted anti-cancer effect on the human body $[4,5]$. Studies focused on selenium (Se) and the other heavy metals in the soils cultivating rubber and pepper found abundant $\mathrm{Se}$ in soil in the Hainan province [6-8]. Camellia oleifera is an important and major source of edible oil in South China $[9,10]$. It has a long history of planting and utilization in Hainan province. Also known as 'pomelo on the hill', Camellia oil from Hainan province is of high quality due to excellent production environment. Studies have been published on Camellia oleifera germplasm resources [11], varieties

*Address correspondence to this author at the Hunan Provincial Cooperative Innovation Center of Non-wood Forest Cultivation and Utilization, Central South University of Forestry and Technology, Changsha, Hunan, 410004, China; Tel: +86-073185623406; Fax: +86-073185623406;

E-mail: tanxiaofengen@126.com selection [12], ecological adaptability [13], and high yield cultivation techniques [14]. However, the correlation between Se and heavy metal contents in soil and their corresponding contents in Camellia oleifera have yet to be reported. In the current study, 18 forests of Camellia oleifera from 11 major production counties in Hainan province were selected to measure the contents of selenium (Se), zinc $(\mathrm{Zn})$, mercury $(\mathrm{Hg}), \mathrm{Cd}$, chromium $(\mathrm{Cr}), \mathrm{Pd}$ and arsenic (As) in soils, roots, leaves, and kernels. The correlation between soil levels of Se and heavy metals and their corresponding contents in Camellia oleifera was analyzed in order to provide a scientific basis for pollution-free and Se-rich oil tea production in Hainan province, China.

\section{MATERIAL AND METHODS}

\subsection{Materials}

The forests of Camellia oleifera covering an area over one acre were selected from 11 counties including Chengmai, Dingan, Qionghai, Wenchang, Qiongzhong, Danzhou, Tunchang, Wuzhishan, Baoting, Baisha, and Haikou. Detailed information was collected regarding the location, latitude, longitude, cultivation method and age of trees (Table 1). 
Table 1. General characteristics of sampling sites.

\begin{tabular}{|c|c|c|c|c|c|c|c|c|}
\hline No. & County (City) & Town & Village & Longitude & Latitude & Altitude (m) & Type of Forest & Age of Forest (a) \\
\hline 1 & Wenchang & Penglai & Hongqi farm & $110^{\circ} 31^{\prime} 53.8^{\prime \prime}$ & $19^{\circ} 31^{\prime} 43.5^{\prime \prime}$ & 160 & rubber mixed forest & 45 \\
\hline 3 & Chengmai & Jiale & Potang village & $110^{\circ} 01^{\prime} 36^{\prime \prime}$ & $19^{\circ} 35^{\prime} 02^{\prime \prime}$ & 100 & artificial pure forest & 80 \\
\hline 5 & Chengmai & Zhongxing & Liwan village & $110^{\circ} 54^{\prime} 38^{\prime \prime}$ & $19^{\circ} 37^{\prime} 57^{\prime \prime}$ & 122 & rubber mixed forest & 82 \\
\hline 6 & Dingan & Fuwen & Baihe village & $110^{\circ} 12^{\prime} 21.3^{\prime \prime}$ & $19^{\circ} 26^{\prime} 47.7^{\prime \prime}$ & 110 & artificial pure forest & 100 \\
\hline 7 & Dingan & Long-Hu & Gaolin village & $110^{\circ} 29^{\prime} 0.2^{\prime \prime}$ & $19^{\circ} 35^{\prime} 04.6^{\prime \prime}$ & 60 & artificial pure forest & 10 \\
\hline 8 & Danzhou & Dacheng & Qiangtu village & $109^{\circ} 24^{\prime} 38.1^{\prime \prime}$ & $19^{\circ} 30^{\prime} 40.8^{\prime \prime}$ & 155 & artificial pure forest & 210 \\
\hline 11 & Baisha & Xishui & Shihan village & $109^{\circ} 32^{\prime} 19.2^{\prime \prime}$ & $19^{\circ} 12^{\prime} 33.4^{\prime \prime}$ & 210 & artificial pure forest & 32 \\
\hline 12 & Qiongzhong & Changzheng & Xinzhai village & $109^{\circ} 51^{\prime} 46^{\prime \prime}$ & $18^{\circ} 58^{\prime} 33^{\prime \prime}$ & 352 & rubber mixed forest & 43 \\
\hline 13 & Qiongzhong & Wanling & Shiwan village & $109^{\circ} 57^{\prime} 13.8^{\prime \prime}$ & $19^{\circ} 10^{\prime} 26.7^{\prime \prime}$ & 276 & artificial pure forest & 65 \\
\hline 14 & Qionghai & Huishan & Zhongjiu village & $110^{\circ} 18^{\prime} 20.2^{\prime \prime}$ & $19^{\circ} 05^{\prime} 17.6^{\prime \prime}$ & 60 & artificial pure forest & 300 \\
\hline 15 & Qionghai & Jiaji & Hongxing committee & $110^{\circ} 27^{\prime} 36^{\prime \prime}$ & $19^{\circ} 15^{\prime} 02^{\prime \prime}$ & 40 & areca-nut mixed forest & 54 \\
\hline 16 & Wuzhishan & Changhao & Shiha village & $109^{\circ} 27^{\prime} 55.7^{\prime \prime}$ & $18^{\circ} 40^{\prime} 47.6^{\prime \prime}$ & 728 & artificial pure forest & 62 \\
\hline
\end{tabular}

Five mid-sized trees from each forest were selected as the samples. The samples of soil were collected by wooden spade one meter away from the sampling trees, at a depth of 0 to $20 \mathrm{~cm}$. The soil samples were then mixed and stored up to $1 \mathrm{~kg}$ by quartation method. The slim roots of $5 \mathrm{~g}$ from each tree sample were taken after removing the surface soil. Forty mature leaves were collected from east, south, west, and north of each tree; four mid-sized fruits were collected as well.

Soil samples were naturally air-dried indoors and filtered through $0.147 \mathrm{~mm}$ nylon sieve. The plant samples were repeatedly cleaned by water and deionized water thrice to remove dirt and mud. The kernels were removed from the fruits. The leaves, roots and kernels were fixed at $105^{\circ} \mathrm{C}$ for 30 minutes and crushed after drying at $65^{\circ} \mathrm{C}$ to obtain a constant weight.

\subsection{Determination of Se and Heavy Metals in Soil}

The soil contents of $\mathrm{Se}, \mathrm{Hg}$, and $\mathrm{As}$ were measured according to the standard industrial methods in NYT11042006 (Chinese Standard, the same below), NY/T 1121.102006 and NY/T 1121.11-2006 using atomic fluorescence spectrophotometry (AFS-9120, Beijing Jitian Instruments Co., Ltd, China). The soil contents of $\mathrm{Zn}, \mathrm{Cr}, \mathrm{Pb}$ and $\mathrm{Cd}$ were measured according to the processing methods described in the national standard (GB/T 17141-1997) by inductively coupled plasma mass spectrometry (ICP-MS) (ELAN, DRC-e, PerkinElmer, US).

\subsection{Determination of Se and Heavy Metals in Plant}

The content of $\mathrm{Se}$ in roots, leaves, and kernels of Camellia oleifera was measured according to the processing method described in the Chinese national standard GB/T 21729-2008. Zn, As, Cr, Hg, Pd and Cd were measured according to the processing method described in the national standards GB/T 5009.14-2003, GB/T 5009.11-2003, GB/T 5009.123-2003, GB/T 5009.17-2003, GB 5009.12-2010, and GB/T 5009.15-2003, respectively.

\subsection{Statistical Analysis}

All measurements were performed in triplicate. Excel 2010 and SPSS 17.0 software were utilized for statistical analysis. Certain data and analysis were absent due to undetectable low content of metal elements. 
Table 2. Se and six heavy metals in the forest soil of Camellia oleifera in Hainan $\left(\mathrm{mg} \cdot \mathrm{kg}^{-1}\right)$.

\begin{tabular}{|c|c|c|c|c|c|c|c|c|}
\hline Location & pH & $\mathbf{Z n}$ & $\mathrm{Cr}$ & $\mathbf{P b}$ & Cd & As & $\mathbf{H g}$ & Se \\
\hline Wenchang-Penglai & $4.5 \pm 0.2$ & $110 \pm 0.6$ & $267 \pm 0.4$ & $5.51 \pm 0.2$ & $0.1500 \pm 0.030$ & $1.34 \pm 0.05$ & $0.050 \pm 0.012$ & $1.540 \pm 0.135$ \\
\hline Chengmai-Jiale & $4.8 \pm 0.3$ & $36.0 \pm 0.3$ & $10.4 \pm 0.2$ & $25.7 \pm 0.1$ & $0.0569 \pm 0.003$ & $1.81 \pm 0.06$ & $0.030 \pm 0.001$ & $1.100 \pm 0.062$ \\
\hline Chengmai-Zhongxing & $4.5 \pm 0.2$ & $8.26 \pm 0.2$ & $5.64 \pm 0.3$ & $7.93 \pm 0.2$ & $0.0195 \pm 0.002$ & $1.48 \pm 0.07$ & $0.017 \pm 0.001$ & $0.489 \pm 0.032$ \\
\hline Dingan-Fuwen & $4.6 \pm 0.3$ & $42.7 \pm 0.3$ & $39.9 \pm 0.3$ & $27.9 \pm 0.4$ & $0.0491 \pm 0.004$ & $6.40 \pm 0.36$ & $0.059 \pm 0.004$ & $0.996 \pm 0.099$ \\
\hline Dingan-Longhu & $4.2 \pm 0.1$ & $98.5 \pm 0.4$ & $174 \pm 0.4$ & $37.4 \pm 0.4$ & $0.1420 \pm 0.007$ & $1.88 \pm 0.05$ & $0.072 \pm 0.003$ & $1.610 \pm 0.035$ \\
\hline Danzhou-Dancheng & $4.7 \pm 0.2$ & $65.0 \pm 0.5$ & $81.0 \pm 0.5$ & $25.8 \pm 0.4$ & $0.0521 \pm 0.007$ & $2.61 \pm 0.15$ & $0.118 \pm 0.007$ & $0.999 \pm 0.095$ \\
\hline Baisha-Xishui & $5.6 \pm 0.2$ & $30.3 \pm 0.6$ & $16.4 \pm 0.6$ & $19.4 \pm 0.6$ & $0.0569 \pm 0.003$ & $2.46 \pm 0.07$ & $0.031 \pm 0.002$ & $0.665 \pm 0.055$ \\
\hline Qiongzhong-Changzheng & $5.3 \pm 0.2$ & $65.2 \pm 0.4$ & $42.9 \pm 0.5$ & $38.3 \pm 0.4$ & $0.0569 \pm 0.003$ & $1.72 \pm 0.19$ & $0.053 \pm 0.003$ & $1.150 \pm 0.178$ \\
\hline Qiongzhong-Wanling & $5.0 \pm 0.3$ & $26.0 \pm 0.4$ & $54.2 \pm 0.3$ & $28.2 \pm 0.3$ & $0.0504 \pm 0.002$ & $1.18 \pm 0.17$ & $0.065 \pm 0.004$ & $1.700 \pm 0.142$ \\
\hline Qionghai-Huishan & $4.0 \pm 0.2$ & $20.3 \pm 0.7$ & $17.1 \pm 0.4$ & $10.1 \pm 0.9$ & $0.0570 \pm 0.008$ & $1.21 \pm 0.10$ & $0.040 \pm 0.014$ & $0.520 \pm 0.087$ \\
\hline Qionghai-Jiaji & $4.6 \pm 0.3$ & $96.4 \pm 0.4$ & $43.6 \pm 0.4$ & $37.6 \pm 0.4$ & $0.3070 \pm 0.022$ & $4.28 \pm 0.30$ & $0.110 \pm 0.021$ & $2.110 \pm 0.173$ \\
\hline Wuzhishan-Changhao & $5.4 \pm 0.1$ & $55.0 \pm 0.5$ & $9.32 \pm 0.4$ & $30.8 \pm 0.4$ & $0.1260 \pm 0.024$ & $2.87 \pm 0.33$ & $0.060 \pm 0.003$ & $0.804 \pm 0.031$ \\
\hline
\end{tabular}

\section{RESLUTS AND ANALYSIS}

\subsection{Soil Contents of Se and Heavy Metals}

It was found from 18 forests that Se content ranged between 0.480 and $2.110 \mathrm{mg} / \mathrm{kg}$, which was high according to the classification method [3]. The Se content exceeded 1.0 $\mathrm{mg} / \mathrm{kg}$ in 10 forests such as in Penglai of Wenchang county. All the soil samples were acidic, and the heavy metal content was relatively low; the 'Soil Environmental Quality Standard' (GB, 15618 - 1995) was used as a reference. The As and $\mathrm{Hg}$ contents of all the tested regions were lower than first-grade standard level. The $\mathrm{Zn}$ content was lower than first-grade standard level except of Penglai in Wenchang. The $\mathrm{Cr}$ content of all the tested regions was lower than the first-grade standard level except for Penglai in Wenchang county, Dongshan in Haikou county, and Longhu in Dingan county. Though $\mathrm{Pb}$ content of six counties such as Longhu in Dingan county exceeded first-grade standard level, all tested samples were lower than second-grade standard. The $\mathrm{Cd}$ content in all tested regions was lower than natural background, except in Jiaji of Qionghai county, which was higher than second-grade. All tested soil samples fulfilled the requirements of soil environmental quality for green food production using 'green food producing area environment quality’ (NY/T 319 - 2013) as reference, except soil $\mathrm{Cr}$ in Penglai of Wenchang county, Dongshan of Haikou county, and Longhu of Dingan county, soil $\mathrm{Pb}$ in Nankun of Tunchang county, and soil Cd in Jiaji of Qionghai county (Table 2).

\subsection{Se and Heavy Metals Contents in Plant}

As shown in Table 3, there was difference in all root samples obtained from 18 forests in terms of Se and heavy metals contents. The Se content in roots was relatively low, with the maximum of only $0.104 \mathrm{mg} / \mathrm{kg}$ being the highest in Heling farm and Jiale in Chengmai county, followed by Wuzhishan county. The $\mathrm{Zn}, \mathrm{Cr}$ and $\mathrm{Cd}, \mathrm{Pb}, \mathrm{As}$ and $\mathrm{Hg}$ contents in roots were the highest in Nankun of Tunchang county, Jiale in Chengmai county, Changhao of Wuzhishan county, Dacheng of Danzhou county and Heling farm of Chengmai county, respectively.

As shown in Table 4, Se content in leaves of Camellia oleifera was the highest in Heling farm of Chengmai county, followed by Jiale of Chengmai county; and it was the lowest 
Table 3. Se and six heavy metals in the roots of Camellia oleifera in Hainan $\left(\mathrm{mg} \cdot \mathrm{kg}^{-1}\right)$.

\begin{tabular}{|c|c|c|c|c|c|c|c|}
\hline Location & Zn & $\mathrm{Cr}$ & $\mathbf{P b}$ & Cd & As & Hg & Se \\
\hline Wenchang-Penglai & $47.1 \pm 0.2$ & $26.10 \pm 0.27$ & $2.90 \pm 0.19$ & $0.52 \pm 0.10$ & $0.13 \pm 0.01$ & $<0.01$ & $<0.02$ \\
\hline Haikou-Dongshan & $38.6 \pm 0.8$ & $13.26 \pm 1.24$ & $6.18 \pm 0.16$ & $0.33 \pm 0.02$ & $0.31 \pm 0.01$ & $0.042 \pm 0.001$ & $<0.02$ \\
\hline Chengmai-Jiale & $58.7 \pm 0.2$ & $53.16 \pm 0.13$ & $15.4 \pm 0.32$ & $1.60 \pm 0.15$ & $0.29 \pm 0.02$ & $0.110 \pm 0.024$ & $0.092 \pm 0.004$ \\
\hline Chengmai-Heling farm & $17.9 \pm 0.4$ & $12.79 \pm 0.26$ & $6.30 \pm 0.28$ & $0.54 \pm 0.17$ & $0.16 \pm 0.02$ & $0.220 \pm 0.012$ & $0.104 \pm 0.004$ \\
\hline Chengmai-Zhongxing & $31.1 \pm 1.9$ & $29.08 \pm 0.25$ & $9.10 \pm 0.31$ & $1.30 \pm 0.14$ & $0.22 \pm 0.02$ & $0.036 \pm 0.002$ & $<0.02$ \\
\hline Dingan-Fuwen & $13.2 \pm 0.5$ & $31.78 \pm 0.25$ & $25.1 \pm 0.30$ & $0.83 \pm 0.08$ & $0.35 \pm 0.01$ & $0.045 \pm 0.003$ & $0.030 \pm 0.001$ \\
\hline Dingan-Longhu & $15.4 \pm 0.3$ & $30.71 \pm 0.14$ & $6.30 \pm 0.17$ & $0.43 \pm 0.06$ & $0.17 \pm 0.01$ & $0.032 \pm 0.002$ & $<0.02$ \\
\hline Danzhou-Dancheng & $12.4 \pm 0.2$ & $48.18 \pm 0.15$ & $23.9 \pm 0.20$ & $1.30 \pm 0.14$ & $0.72 \pm 0.02$ & $0.041 \pm 0.002$ & $0.034 \pm 0.002$ \\
\hline Tunchang-Nankun & $61.2 \pm 0.2$ & $31.54 \pm 0.29$ & $23.2 \pm 0.41$ & $0.95 \pm 0.14$ & $0.20 \pm 0.02$ & $0.072 \pm 0.002$ & $<0.02$ \\
\hline Tunchang-Poxing & $31.1 \pm 0.2$ & $16.86 \pm 0.24$ & $13.8 \pm 0.19$ & $0.58 \pm 0.07$ & $0.12 \pm 0.01$ & $<0.01$ & $<0.02$ \\
\hline Baisha-Xishui & $21.2 \pm 0.3$ & $7.42 \pm 0.16$ & $22.3 \pm 0.26$ & $1.40 \pm 0.13$ & $0.50 \pm 0.04$ & $0.048 \pm 0.002$ & $0.032 \pm 0.001$ \\
\hline Qiongzhong-Changzheng & $9.5 \pm 0.1$ & $11.68 \pm 0.15$ & $23.3 \pm 0.10$ & $0.88 \pm 0.06$ & $0.10 \pm 0.03$ & $0.048 \pm 0.001$ & $0.042 \pm 0.006$ \\
\hline Qiongzhong-Wanling & $8.7 \pm 0.2$ & $14.60 \pm 0.28$ & $17.6 \pm 0.10$ & $0.47 \pm 0.07$ & $<0.1$ & $0.030 \pm 0.006$ & $0.016 \pm 0.002$ \\
\hline Qionghai-Huishan & $6.4 \pm 0.1$ & $14.63 \pm 0.46$ & $3.50 \pm 0.06$ & $0.41 \pm 0.01$ & $<0.1$ & $0.022 \pm 0.001$ & $0.035 \pm 0.007$ \\
\hline Qionghai-Jiaji & $6.0 \pm 0.1$ & $7.85 \pm 0.16$ & $3.10 \pm 0.17$ & $0.05 \pm 0.01$ & $<0.1$ & $0.046 \pm 0.001$ & $0.041 \pm 0.007$ \\
\hline Wuzhishan-Changhao & $25.2 \pm 0.2$ & $26.57 \pm 0.37$ & $49.1 \pm 0.44$ & $0.61 \pm 0.13$ & $0.65 \pm 0.01$ & $0.095 \pm 0.001$ & $0.074 \pm 0.004$ \\
\hline Wuzhishang-Tongshi & $18.7 \pm 0.5$ & $12.16 \pm 0.17$ & $8.55 \pm 0.43$ & $0.40 \pm 0.13$ & $0.10 \pm 0.02$ & $0.088 \pm 0.001$ & $0.080 \pm 0.006$ \\
\hline Baoting-Xiangshui & $14.4 \pm 0.1$ & $10.26 \pm 0.19$ & $6.57 \pm 0.08$ & $0.26 \pm 0.03$ & $0.09 \pm 0.01$ & $0.040 \pm 0.002$ & $0.088 \pm 0.005$ \\
\hline
\end{tabular}

Table 4. Slenium and six heavy metals in the leaves of Camellia oleifera in Hainan ( $\left.\mathrm{mg} \cdot \mathrm{kg}^{-1}\right)$.

\begin{tabular}{|c|c|c|c|c|c|c|c|}
\hline Location & Zn & $\mathrm{Cr}$ & $\mathbf{P b}$ & Cd & As & Hg & Se \\
\hline Wenchang-Penglai & $<0.4$ & $0.82 \pm 0.05$ & $0.42 \pm 0.05$ & $0.045 \pm 0.006$ & $<0.1$ & $<0.01$ & $0.025 \pm 0.004$ \\
\hline Haikou-Dongshan & $<0.4$ & $1.35 \pm 0.12$ & $0.60 \pm 0.04$ & $0.028 \pm 0.004$ & $<0.1$ & $0.022 \pm 0.003$ & $0.057 \pm 0.002$ \\
\hline Chengmai-Jiale & $<0.4$ & $2.28 \pm 0.05$ & $0.54 \pm 0.05$ & $<0.01$ & $<0.1$ & $0.032 \pm 0.004$ & $0.077 \pm 0.005$ \\
\hline Chengmai-Heling farm & $<0.4$ & $0.59 \pm 0.04$ & $1.50 \pm 0.07$ & $<0.01$ & $<0.1$ & $<0.01$ & $0.120 \pm 0.003$ \\
\hline Chengmai-Zhongxing & $<0.4$ & $1.56 \pm 0.05$ & $1.00 \pm 0.04$ & $<0.01$ & $<0.1$ & $0.095 \pm 0.005$ & $0.056 \pm 0.010$ \\
\hline Dingan-Fuwen & $<0.4$ & $2.45 \pm 0.05$ & $1.30 \pm 0.07$ & $0.012 \pm 0.002$ & $<0.1$ & $0.014 \pm 0.005$ & $0.046 \pm 0.005$ \\
\hline Dingan-Longhu & $<0.4$ & $3.03 \pm 0.07$ & $0.66 \pm 0.05$ & $0.031 \pm 0.006$ & $<0.1$ & $0.035 \pm 0.005$ & $0.045 \pm 0.005$ \\
\hline Danzhou-Dancheng & $<0.4$ & $0.89 \pm 0.04$ & $0.51 \pm 0.05$ & $0.024 \pm 0.005$ & $<0.1$ & $0.086 \pm 0.005$ & $<0.02$ \\
\hline Tunchang-Nankun & $<0.4$ & $1.38 \pm 0.07$ & $0.30 \pm 0.03$ & $0.022 \pm 0.005$ & $<0.1$ & $<0.01$ & $0.020 \pm 0.002$ \\
\hline Tunchang-Poxing & $<0.4$ & $1.99 \pm 0.11$ & $0.30 \pm 0.02$ & $0.018 \pm 0.004$ & $<0.1$ & $0.046 \pm 0.005$ & $0.064 \pm 0.005$ \\
\hline
\end{tabular}


Table 4. contd...

\begin{tabular}{|c|c|c|c|c|c|c|c|}
\hline Location & $\mathbf{Z n}$ & $\mathrm{Cr}$ & $\mathbf{P b}$ & Cd & As & $\mathrm{Hg}$ & Se \\
\hline Baisha-Xishui & $<0.4$ & $1.44 \pm 0.11$ & $0.50 \pm 0.08$ & $0.089 \pm 0.007$ & $<0.1$ & $0.030 \pm 0.002$ & $0.039 \pm 0.006$ \\
\hline Qiongzhong-Wanling & $<0.4$ & $0.06 \pm 0.01$ & $0.15 \pm 0.01$ & $0.013 \pm 0.003$ & $<0.1$ & $0.045 \pm 0.003$ & $0.059 \pm 0.007$ \\
\hline Qionghai-Jiaji & $<0.4$ & $0.48 \pm 0.01$ & $0.09 \pm 0.02$ & $0.034 \pm 0.006$ & $<0.1$ & $0.021 \pm 0.005$ & $0.025 \pm 0.005$ \\
\hline Wuzhishan-Changhao & $<0.4$ & $1.52 \pm 0.05$ & $0.34 \pm 0.05$ & $0.015 \pm 0.005$ & $<0.1$ & $0.062 \pm 0.007$ & $0.047 \pm 0.006$ \\
\hline Wuzhishang- Tongshi & $<0.4$ & $1.55 \pm 0.08$ & $0.09 \pm 0.01$ & $0.012 \pm 0.006$ & $<0.1$ & $0.073 \pm 0.003$ & $0.025 \pm 0.002$ \\
\hline Baoting-Xiangshui & $<0.4$ & $0.28 \pm 0.02$ & $0.25 \pm 0.01$ & $0.014 \pm 0.001$ & $<0.1$ & $0.038 \pm 0.006$ & $0.035 \pm 0.004$ \\
\hline
\end{tabular}

Table 5. Se and six heavy metals in Camellia oleifera Kernels in Hainan ( $\left.\mathrm{mg}^{\circ} \mathrm{kg}^{-1}\right)$.

\begin{tabular}{|c|c|c|c|c|c|c|c|}
\hline Location & $\mathbf{Z n}$ & $\mathrm{Cr}$ & $\mathbf{P b}$ & Cd & As & Hg & Se \\
\hline Wenchang-Penglai & $<0.4$ & $0.59 \pm 0.03$ & $0.04 \pm 0.01$ & $0.024 \pm 0.002$ & $<0.1$ & $<0.01$ & $0.038 \pm 0.004$ \\
\hline Haikou-Dongshan & $<0.4$ & $1.35 \pm 0.04$ & $0.59 \pm 0.02$ & $0.020 \pm 0.002$ & $<0.1$ & $0.011 \pm 0.001$ & $<0.02$ \\
\hline Chengmai-Jiale & $<0.4$ & $4.54 \pm 0.06$ & $0.06 \pm 0.01$ & $0.031 \pm 0.004$ & $<0.1$ & $0.010 \pm 0.004$ & $<0.02$ \\
\hline Chengmai-Heling farm & $<0.4$ & $4.25 \pm 0.05$ & $0.21 \pm 0.04$ & $0.025 \pm 0.005$ & $<0.1$ & $<0.01$ & $<0.02$ \\
\hline Chengmai-Zhongxing & $<0.4$ & $0.63 \pm 0.05$ & $0.94 \pm 0.01$ & $0.039 \pm 0.004$ & $<0.1$ & $0.012 \pm 0.001$ & $<0.02$ \\
\hline Dingan-Fuwen & $<0.4$ & $0.16 \pm 0.01$ & $<0.05$ & $0.019 \pm 0.004$ & $<0.1$ & $0.039 \pm 0.004$ & $0.085 \pm 0.006$ \\
\hline Dingan-Longhu & $4.80 \pm 0.1$ & $0.18 \pm 0.01$ & $0.20 \pm 0.01$ & $0.016 \pm 0.004$ & $<0.1$ & $0.037 \pm 0.005$ & $0.060 \pm 0.006$ \\
\hline Danzhou-Dancheng & $3.80 \pm 0.1$ & $0.22 \pm 0.02$ & $0.14 \pm 0.02$ & $0.030 \pm 0.002$ & $<0.1$ & $0.032 \pm 0.004$ & $0.041 \pm 0.001$ \\
\hline Tunchang-Nankun & $11.1 \pm 0.1$ & $0.22 \pm 0.03$ & $0.08 \pm 0.01$ & $0.023 \pm 0.004$ & $<0.1$ & $0.015 \pm 0.004$ & $<0.02$ \\
\hline Tunchang-Poxing & $11.7 \pm 0.2$ & $3.92 \pm 0.06$ & $0.08 \pm 0.01$ & $0.024 \pm 0.004$ & $<0.1$ & $<0.01$ & $<0.02$ \\
\hline Baisha-Xishui & $11.9 \pm 0.1$ & $0.60 \pm 0.01$ & $0.15 \pm 0.03$ & $0.025 \pm 0.004$ & $<0.1$ & $0.010 \pm 0.002$ & $<0.02$ \\
\hline Qiongzhong-Changzheng & $9.50 \pm 0.1$ & $0.29 \pm 0.04$ & $0.20 \pm 0.02$ & $0.048 \pm 0.003$ & $<0.1$ & $0.026 \pm 0.003$ & $<0.02$ \\
\hline Qiongzhong-Wanling & $1.40 \pm 0.1$ & $0.40 \pm 0.05$ & $<0.05$ & $0.018 \pm 0.003$ & $<0.1$ & $0.018 \pm 0.006$ & $<0.02$ \\
\hline Qionghai-Huishan & $10.8 \pm 0.1$ & $4.13 \pm 0.04$ & $0.14 \pm 0.02$ & $0.016 \pm 0.005$ & $<0.1$ & $0.011 \pm 0.005$ & $<0.02$ \\
\hline Qionghai-Jiaji & $6.00 \pm 0.1$ & $2.74 \pm 0.05$ & $0.31 \pm 0.01$ & $0.037 \pm 0.022$ & $<0.1$ & $0.013 \pm 0.004$ & $<0.02$ \\
\hline Wuzhishan-Changhao & $16.8 \pm 0.1$ & $1.55 \pm 0.04$ & $0.19 \pm 0.02$ & $0.013 \pm 0.004$ & $<0.1$ & $<0.01$ & $<0.02$ \\
\hline Wuzhishang- Tongshi & $24.3 \pm 0.1$ & $0.65 \pm 0.04$ & $0.33 \pm 0.03$ & $0.036 \pm 0.006$ & $<0.1$ & $0.0135 \pm 0.004$ & $<0.02$ \\
\hline Baoting-Xiangshui & $17.7 \pm 0.1$ & $0.12 \pm 0.02$ & $0.13 \pm 0.01$ & $0.014 \pm 0.002$ & $<0.1$ & $0.0120 \pm 0.001$ & $0.022 \pm 0.005$ \\
\hline
\end{tabular}

in Dacheng of Danzhou county and Huishan of Qionghai county. Cr content in leaves was the highest in Longhu of Dingan county, followed by Fuwen of Dingan county. Pd, $\mathrm{Cd}$, and $\mathrm{Hg}$ contents in the leaves were the highest in Heling farm of Chengmai county, Xishui of Baisha county, and Zhongxing of Chengmai county, respectively. The $\mathrm{Cd}$ content was undetectable in leaves in four counties including the Heling farm of Chengmai county; the content of $\mathrm{Hg}$ was undetectable in leaves in three counties which include Penglai of Wenchang county. The $\mathrm{Zn}$ and As contents in leaves from all 18 counties were undetectable.

As shown in Table 5, Se content in kernels of Camellia oleifera was very low, only detectable in five regions and 
Table 6. Coefficients of Se and heavy metal elements in soils and different parts of Camellia oleifera in Hainan.

\begin{tabular}{|c|c|c|c|c|c|c|c|}
\hline & Zn & Cr & Pb & Cd & As & Hg \\
\hline \hline Root & 0.191 & 0.134 & $0.308^{*}$ & $-0.497 * *$ & $0.436^{* *}$ & 0.075 \\
\hline Leaf & - & 0.088 & -0.176 & -0.127 & - & 0.214 \\
\hline Kernel & -0.107 & -0.218 & 0.015 & $0.809^{* *}$ & - & 0.139 \\
\hline
\end{tabular}

Note: **indicates correlated at $\mathrm{P}<0.01$ level; *indicates correlated at $\mathrm{P}<0.05$ level Certain data are absent due to undetactable content of $\mathrm{Zn}$ and $\mathrm{Se}$ in leaves and As and Se in kernels in some areas. Similar conditions apply in the following tables.

Table 7. Coefficients of Se and heavy metal levels in roots, leaves, and seeds of Camellia oleifera in Hainan.

\begin{tabular}{|c|c|c|c|c|c|c|c|}
\hline & $\mathbf{Z n}$ & $\mathbf{C r}$ & $\mathbf{P b}$ & $\mathbf{C d}$ & As & Hg & Se \\
\hline \hline Leaf & - & $0.469^{* *}$ & 0.151 & $0.576^{* *}$ & - & -0.157 & -0.076 \\
\hline Kernel & 0.244 & -0.038 & 0.075 & $-0.305^{*}$ & - & $0.605^{* *}$ & - \\
\hline
\end{tabular}

Table 8. Coefficients of Se and heavy metal concentrations in roots and leaves of Camellia oleifera in Hainan.

\begin{tabular}{|c|c|c|c|c|c|c|}
\hline & Zn & Cr & Pb & Cd & As & Hg \\
\hline \hline Root & -0.141 & -0.079 & -0.147 & -0.095 & $-0.368^{*}$ & -0.119 \\
\hline Leaf & - & 0.239 & -0.057 & -0.025 & - & 0.159 \\
\hline
\end{tabular}

was highest in Fuwen of Dingan county. Zinc content in kernels was highest in Tongshi of Wuzhishan county, and undetectable in six regions including Penglai of Wenchang county. Cr content in kernels exceeded $1.0 \mathrm{mg} / \mathrm{kg}$ in seven regions such as Dongshan of Haikou county. Pd content in kernels was over $0.5 \mathrm{mg} / \mathrm{kg}$ in Dongshan of Haikou county and Zhongxin of Chengmai county. The contents of $\mathrm{Cd}$, As and $\mathrm{Hg}$ were very low, undetectable in kernels of all the 18 forests.

\subsection{Correlation of Se and Heavy Metals Between Soil and Roots, Leaves, and Kernels of Camellia oleifera}

Significant positive correlation in $\mathrm{As}$ and $\mathrm{Pb}$ contents was observed between soil and roots of Camellia oleifera. However, significant negative correlation of $\mathrm{Cd}$ content between soil and roots of Camellia oleifera was observed. Significant positive correlation between soil and kernels was only found for Cd content; suggesting that only soil As and $\mathrm{Pb}$ content showed high biological availability for Camellia oleifera (Table 6).

To investigate the transferability of metal elements from roots to leaves and kernels, the correlation study was used to compare the contents of each element in different parts of Camellia oleifera (Table 7). It was found that there was significant positive correlation between roots and leaves in terms of $\mathrm{Cr}$ and $\mathrm{Cd}$ content; and there was positive correlation between roots and leaves in terms of $\mathrm{Pd}$ content. However, significant negative correlation was found between roots and leaves in terms of $\mathrm{Hg}$ and $\mathrm{Se}$ contents. In addition, there was significant positive correlation between roots and kernels with regard to $\mathrm{Hg}$ content; whereas, significant negative correlation was found between roots and kernels in terms of $\mathrm{Cd}$ content, implying that $\mathrm{Cr}$ and $\mathrm{Cd}$ are easily translocated from roots to leaves, and $\mathrm{Hg}$ from roots to kernels.

\subsection{Correlation Between Se and Six Metal Elements in Roots and Leaves}

The relationship between the roots and leaves regarding the Se content and 6 metal elements is shown in Table 8. There was negative correlation of content between Se and the other six metal elements in the roots of Camellia oleifera, and significant negative correlation was found between $\mathrm{Se}$ and $\mathrm{As}$ in roots. A positive correlation between $\mathrm{Se}$ and $\mathrm{Cr}$ content as well as $\mathrm{Hg}$ in leaves, and negative correlation between $\mathrm{Se}$ and $\mathrm{Pd}$ as well as $\mathrm{Cd}$, suggested that Se reduced the absorption of heavy metals by roots, especially the absorption of As.

\section{DICUSSION}

Se-enriched soil is widely distributed in Hainan Island of China. Se content was high in the soils of Haikou and Chengmai counties [15]. It has been confirmed in the current study that Se content ranged between 0.489 and $2.110 \mathrm{mg} / \mathrm{kg}$ in 18 forests of Camellia oleifera, which is higher than that in the soil of rice paddy fields [15]. The soil Se content was higher than $1.0 \mathrm{mg} / \mathrm{kg}$ in 10 forests out of 18 . However, there was no significant correlation between the soil and roots of Camellia oleifera with respect to Se content. The Se content in leaves and kernels was also low, probably due to acidic soil conditions and impaired biological availability of Se [16]. Our findings suggest that blindly supplementing Se fertilizer in the nutrient management of 
Camellia oleifera should be avoided. Instead, alkaline fertilizer to promote the activation of Se and improve its bioavailability in soil [17], or screen for suitable Camellia oleifera varieties should be recommended to produce effective and economical Se-enriched camellia oil $[2,18]$. The average content of heavy metals in soil was low in Camellia oleifera forests of Hainan province and fulfilled the requirements for green-food production. However, the heavy metal content in soil and Camellia trees greatly varied geographically with different cultivation methods, which might be attributed to diverse soil characteristics and use of chemical fertilizers [19]. Therefore, instead of chemical fertilizers containing heavy metals, ecofriendly cultivation using manures [20] and forest intercropping [21] should be adopted.

The content of heavy metals in roots was higher than that in leaves and kernels, suggesting that Camellia restricts the translocation of heavy metals from roots to leaves and kernels [22], which is the key to successful utilization of seeds of Camellia oleifera. The mechanism of heavy metal distribution in the plant following absorption from soils should be further elucidated. Also, production processes that limit heavy metal transfer from roots to kernels should be adopted. Variations in heavy metal accumulations by different organs of plants are a consequence of species and climate diversity [23], which is also known as heavy metal enrichment coefficient.

\section{CONCLUSION}

In the current study, the enrichment coefficient was relatively higher for $\mathrm{Zn}, \mathrm{Cr}$ and $\mathrm{Pb}$ by the roots of Camellia oleifera, which was consistent with the study based on tropical trees such as Casuarina equisetifolia [24]. Significant positive and negative correlations were found between soil and roots with regard to $\mathrm{As}$ and $\mathrm{Pb}$ contents, respectively, implying that $\mathrm{As}$ and $\mathrm{Pb}$ are easily activated and absorbed by Camellia oleifera, since they are associated with high utilization efficiency of phosphate [25]. Therefore, it is necessary to further analyze the relationship between essential elements and heavy metal activation in Camellia [26]. A significant positive correlation between the roots and leaves in terms of $\mathrm{Cr}$ and $\mathrm{Cd}$ contents was observed. A significant positive correlation between roots and kernels in terms of $\mathrm{Hg}$ content suggested that the transportation of $\mathrm{Hg}$ into fruits was relatively easier. It is thus essential to control the $\mathrm{Hg}$ content in soil to reduce the risk of $\mathrm{Hg}$ absorption. Se and six heavy metals were in negative correlation in roots, especially Se and As, implying that strengthing of Se enrichment effectively reduced the accumulation of heavy metals [27]. Therefore, in addition to increasing Se bioactivity in soil, Se supplementation through leaves is recommended to regulate heavy metal distribution in fruits [28], after carrying out additional testing and analysis.

\section{CONFLICT OF INTEREST}

The authors confirm that this article content has no conflicts of interest.

\section{ACKNOWLEDGEMENTS}

This work is supported by Special Fund for Forestry Scientific Research in the Public Interest (201504705).

\section{REFERENCES}

[1] Li B, Zhao C. Current situation of heavy metals pollution in soil at farmland and detection technologies analysis in China. J Agric Resour Environ 2013; 30: 1-7.

[2] Geng JM, Wu LL, Yu A, Tang SM. Screening enriched-selenium hybrid rice cultivars of Hainan province. Chin Agric Sci Bull 2010; 26: 376-80.

[3] Yang Y, Liu X, Ning C, et al. Effects of foliar feeding of selenium on fruit quality and accumulation of cadmium, lead and mercury in sweet persimmon. Acta Hort Sin 2013; 40: 523-30.

[4] Chen S, Sun G, Chen Z, Chen F, Zhu YG. Progresses on selenium metabolism and interaction with heavy metals in higher plants. Plant Physiol J 2014; 50: 612-24.

[5] Xiong SJ, Liu JY, Xu WH, Xie W. Progresses on selenium metabolism and interaction with heavy metals in higher plants. Environ Sci 2015; 36: 286-94.

[6] Lin D, Wang L, Zhang Y. Present situation of soil heavy metals in banana gardens of Hainan and its changing tendency. J Saf Environ 2006; 6: 54-8.

[7] Guo Y, Fu Y, Bai X, Yang Y, Zhang G. Source analysis and evaluation of soil heavy metals in pepper fields in Hainan Province. Chin J Soil Sci 2012; 43: 54-8.

[8] Tan Y, Wei J, Chen Z, Gao W. Distribution and evaluation of heavy metal contents in the soil of Areca catechu plantations in Hainan. Chin Environ Sci 2011; 31: 815-9.

[9] Zhuang R. Oiltea in China. Beijing: Forestry press in China, 2012, pp. 3-5.

[10] State Forestry Bureau of China, National Development Planning of Oiltea(2009 2020). Beijing: Forestry press in China, 2012, pp. 15-8.

[11] Yuan J, Han Z, He S, Huang L, Zhou N. Investigation and cluster analysis of main morphological and economical characters for oiltea resource in Hainan. J Plant Genet Resour 2014; 15: 1380-84.

[12] Yang W, Chen L, Wang X. Preliminary report on introduction and trial planting of subtropical excellent varieties in Hainan area. Acta Agricul Jiangxi 2012; 24: 63-5.

[13] Yang W, Chen L, Wang X. Analysis on ecological adaptability of Camellia oleifera in central area of Hainan. Acta Agricul Jiangxi 2010; 22: 93-5.

[14] Fu D, Chen L, Yang W. High yielding cultivation technique for oil Camellia in Hainan. Chin J Trop Agric 2012; 32: 23-7.

[15] Geng J, Wang W, Wen C, Yi Z, Tang S. Concentrations and distributions of selenium and heavy metals in Hainan paddy soil and assessment of ecological security. Acta Ecol Sin 2012; 32: 3477-86.

[16] Punz WF, Sieghardt H. The response of roots of herbaceous plant species to heavy metals. Environ Exp Bot 1993; 33: 85-98.

[17] Du Q, Chen C, Zeng B. Ways to increase effective selenium in laterite soil of Hainan. Chin. J Trop Agric 2013; 33: 9-12.

[18] Du Q, Zhang Y, Tang S, Long K, Zeng B, Li G. The absorption and distribution mechanisms of selenium from Hainan selenium rich soil by different rice varieties. Soil Fertil Sci Chin 2009; 6: 3740.

[19] He T, Dong L, Liu Y, Shu Y, Luo H, Liu F. Change of physicalchemical properties and heavy mental element in soil from different parent material /rock. J Soil Water Conserv 2006; 6: 15762.

[20] Li X, Peng X, Wu S, Li Z, Feng H, Jiang Z. Effect of arbuscular mycorrhizae on growth, heavy metal uptake and accumulation of Zenia insignis chun seedlings. Environ Sci 2014; 35: 3142-8.

[21] Wei Z, Guo X, Wu Q, Long X. Continuous remediation of heavy metal contaminated soil by co-cropping system enhanced with chelator. Environ Sci 2014; 35: 4305-12.

[22] Dahmani-Muller H, Gelie B, Balabane M, Van F. Strategies of heavy metal uptake by three plant species growing near a metal smelter. Environ Pollut 2000; 109: 231-8.

[23] Weis JS, Weis PH. Metal uptake, transport and release by wetland plants: implications for phytoremediation and restoration. Environ Int 2004; 30: 685-700. 
[24] Jin M, Ding Z, Zhou H, Ye G. Absorption and enrichment of heavy metals by Casuarina equisetifolia of different stand ages in a coastal zone. Chin J Ecol 2014; 33: 2183-7.

[25] Bolan N, Mahimairaja S, Kunhikrishnan A. Phosphorus-arsenic interactions in variable-charge soils in relation to arsenic mobility and bioavailability. Sci Total Environ 2013; 463: 1154-62.

[26] Zhu W, Yang Y, Bi H, Liu Q. Research on hte total bioavailble concentrations and biaoabailabity of $\mathrm{Zn}, \mathrm{Pb}, \mathrm{Cu}$ and $\mathrm{Cd}$ in soils in Hainan province. Acta Mineral Sin 2004; 24: 239-44.
[27] Hu Y, Duan G, Huang Y, Liu Y, Sun G. Interactive effects of different inorganic $\mathrm{As}$ and Se species on their uptake and translocation by rice (Oryza sativa L.) seedlings. Environ Sci Pollut Res 2014; 21: 3955-62.

[28] Zhao J, Gao Y, Li Y, et al. Selenium inhibits the phytotoxicity of mercury in garlic (Allium sativum). Environ Res 2013; 125: 75-81.

Received: August 27, 2014

(C) Yuan et al.; Licensee Bentham Open.

This is an open access article licensed under the terms of the Creative Commons Attribution Non-Commercial License (http://creativecommons.org/licenses/ by-nc/4.0/) which permits unrestricted, non-commercial use, distribution and reproduction in any medium, provided the work is properly cited. 